\title{
Research on Low Carbon Behavior of Tourist Hotels Based on Smart City Development
}

\author{
Yuanchun Huang ${ }^{1}$ and Bingjie $\mathrm{Xu}^{2}$ \\ ${ }^{1}$ Bohai University College of Management \\ ${ }^{2}$ Shenyang Agricultural University College of Economic and Management
}

Keywords: Smart city; Tourist hotel; L ow carbon behavior

\begin{abstract}
Smart City is a new concept of urban development in recent years, it attracted widespread attention as soon as it entered the people's vision. The paper strated from the origin of the smart city concept, combining with the basic laws of the urban evolution and the typical view of the smart city, it analyzed the basic connotation of the smart city and smart city system; based on this, analyzes on how to construct the ecological hotel in the development process of smart city.
\end{abstract}

\section{Definition of Smart City}

The smart city is a concept based on the emerging of information technology, the basic development direction of the Smart City is the sustainable development of the economy, society and environment. The artificial intelligence and human intelligence are the basic tools for a city to becoming smart, they promote the integration of the city's various resources in the areas, optimizing the allocation of the urban core resources.

The smart city itself is a complete system, including five subsystems which are strategic systems, social systems, economic systems, support systems and space systems. From a structural point of view, the structure of smart city system is of with specific hierachy characteristics, containing physical layer, the active layer and the stategic layer three layers with the complexity from low to high. The system model revealed the internal mechanism of the forming, runningand the development of smart city system, through the interconnected contact between strategic systems, social systems, economic systems, support systems, space systems and strategic layer, the active layer, the physical layer.

\section{Influencing Factors of Low Carbon Behavior of Hotel Industry in Smart City}

With the development of low-carbon economy, problems of tourism carbon emission are socially concerned with graduation. Reduce energy consumption and emission of carbon dioxide has become the important measures for dealing with the environment. The impact on the environment of tourism is not so direct and significant as industry, but the massive growth of tourism in promoting the continuous development of world economy also brought many negative effects, the "smokeless industry" also has carbon emissions. The carbon emissions of tourism mainly come from the tourism traffic and hotel industry, carbon emissions from the hotels account for $21 \%$ of the carbon emissions of tourism, is the second largest source of carbon emissions of tourism. With energy crisis and environmental problems becoming increasingly serious, as one of the major tourism enterprises, the hotles is an important representative of urban development and the important service window of modern tourism, its carbon emissions in the process of energy consumption cannot be ignored. It is significant that the implementation of low carbon behavior can improve and strengthen the overall image of the hotel industry, alleviate the energy and enviromental pollution, promote the sustainable development of tourism and even smart cities.

With the fast development of hotels in the world, two questions have influenced the future of hotels in China. The first one is that press on environment has become bigger and bigger produced by hotels; the second is the future development of hotels has been short of advanced theories. In fact, the harmony between hotels and environment has been paid more attention since 1980's. The number of low-carbon research in tourist hotels which are the second major route to carbon 
emission is not proportional to its importance and urgency. The nature of intangibility, variation and synchronization of production and consumption in tourist hotels has resulted in the particularity of low-carbon research in difficult measures of carbon emission, uncertainty for carbon emission unit output as well as low-carbon management with challenging. Which factors drive hotels implement low-carbon behavior? On the basis of a systematic analysis on related literature and theories interpretation, through in depth interviews with hotles emplyees and relevant experts. Low carbon behavior of the hotels is divided into two dimensions: general low carbon behavior and positive low carbon behavior. The driving force of low carbon behaviors in hotels include four internal driving force, internal low carbon management, low carbon technical facilities, low carbon responsibility consciousness, talents and three external driving force, policies and regulations, social norms and economic strength, which are interconnected and coupling between them to promote the implementation of low carbon behavior in hotels.

\section{ImplementLow Carbon Behavior Strategy of Tourist Hotels in the Development of Smart City}

\section{To Cultivate Staff's Economical Consciousness by Training and Stimulation}

In the daily managerial work of hotels, it is significant for the staff to be of economical consciousness, and their consciousness on low carbon should be enhanced by giving their staff the favorable language and material stimulation. As managers of some departments, they should make weekly low carbon training plans for their staff, who will get to know what low carbon is, how to control it, and how important it is to control it by taking part in the training. Meanwhile, the managers should work together with their staff to determine standard low carbon behavior by using scientific methods, and set it as an aim for the staff, who will pay more attention to it and work hard to realize it. In hotels, low carbon control is a long-term task, and the low carbon should be lowered by all means. For example, some files, notice and regulations for its own use of the hotel can be printed on the other side of the used paper, the other side of some paper for financial statements can be used for paper of rough draft, soaps and detergent left over by the guests can be collected and placed in staff's washrooms, broken table cloth can be recycled as a rag, room lighting system should be adjusted according to the change of seasons, lights and air-conditioners should be turned off upon staff's departure, the surplus parts should be made full use of after the food is processed, and so on so forth. Only by doing so, can hotel staff be more conscious of low carbon control and management, so that they will form the economical consciousness.

\section{To Let Every Employee Participate in Low carbon Management}

Every employee in the hotel should be clear that Low carbon control depends on every one in it, regardless of leaders or employees, for hotel activities are conducted by human beings, each of whom plays a crucial role in every functional stage of Low carbon management. Consciousness on low carbon is the concept of low carbon behavior and low carbon management. Every employee should be of this consciousness to participate in low carbon management, which is not only the responsibility of a certain departments or certain leaders, but a thing that matters to everyone, including all the employees. Only by setting up the employee's low carbon consciousness, to establish low carbon initiative. Only in this way can all the measures methods and policies of low carbon management be implemented in an active and smooth way.

To Fix on a low carbon Budget and a Reward and Punishment System Based on low carbon Evaluation

A quantitative way to control low carbon is to design a low carbon budget, which aims at a detailed description for every low carbon. The actual low carbon will be evaluated according to the designed low carbon budget, which guarantees the realization of low carbon control, and which should be made out in a complete, individualized, reasonable and challenging way. Some hotels tend to make evaluation rules for the front-desk departments and somewhat ignore the back-desk ones, which is not appropriate. Some hotels make an evaluation on the total low carbon without excluding some uncontrollable low carbon, such as the commission for payment using credit cards and business tax, which is not fair to some individuals. In addition, the uncontrollable low carbon will make the evaluation result become unfair to the some individual employees, who will lose 
power to go on. Thus, the low carbon budget should be controllably and reasonably designed in accordance with the features of every department, and meanwhile it should be challenging so that every member will make effort to actualize it. If it is too hard on them, the employees will fail to finish it, and if it is easy to complete, then it is of no use controlling it. The standard for the budget should be decided on according to the previous data, characteristics of each department, and future trend of the hotel and its strategies. The standard should be issued monthly by making adjustments to the unreasonable parts, whose causes should be analyzed so that mistakes will be corrected to make the low carbon more controllable later on. The evaluation can be made annually or every half year by rewarding those who do well and punishing those who fail to reach the standard. It can also be made annually or every half year in combination with the good performance award, and in this way, it also serves as an important evaluation standard for the good performance award. When evaluated, the unreasonable low carbon budget standard should be analyzed for its problems that should be put right in the future budget. In evaluation, the variable low carbon can be measured in rates. For example, low carbon rate for food and dishes may be used to evaluate the staff working in the kitchen; low carbon rate for food and drinks, to evaluate those working in the bar; the rate of consumption of cleaning products, porcelain and glass utensils to the income of food and drinks, to evaluate whose in stewarding department; the low carbon rate of consumption of room cleaning products, items used by guests and office supplies to the room revenue, to evaluate those in the guest house department; fees for office supplies and telephone calls, to evaluate those in back-desk departments; fees for repairs and maintenance, to evaluate those in the engineering department; and the staff whose work concerns fixed fees such as telephone tolls can be evaluated in terms of absolute numbers.

\section{To Establish "Human-centered" Concept in Low Carbon Control}

Human plays a fundamental role in management and business dealings. Low carbon control and its implementation rely on the whole working staff of a hotel instead of the financial staff. As a result, to get the maximal and optimal participation and enthusiasm of all the staff, it is crucial to establish the "human-centered" managerial concept in low carbon control so as to make full use of human's value, potential, energy and moral quality, for the staff know better of the hotel's business procedure, service regulations and the expenditure of consumable products in daily dealings, so that they are able to control low carbon anytime and anywhere in almost every occasion. Thus, the effect of low carbon control is significantly improved due to the full play of staff's potential and consciousness on low carbon control.

\section{Acknowledgement}

This paper serves as one of research results for"2015 Liaoning Provincial Fund Project for Social Science"(RegistrationNo.:L15BJY010)and"2016 Education department of Liaoning Province"(Registration No:WY2016002)

\section{Reference}

[1] Sun Aobing, Ji Tongkai, Wu Xiaoqiang, Design and realization of big data open platform for smart city, Journal of Computer Applications,2017.06

[2] An Da, Liang Zhihao,Xu Shouren, Research on the construction of smart city safety based on Big data, Journal of China Academy of Electronics and Information Technology,2016.06

[3] Xu Dan, Liv Yanhong, Wan Xucai,The Interprovincial Differences and Influencing Factors of High-star Hotels Distribution in China, Economic Survey, 2016.05

[4] Huang Lei ,Li Li, Lin Shu,On the Influence Factors of the Consue Intention in Low-carbon Tourism,Journal of Central South University of Forestry\& Technology(Social Sciences),2016.01

[5] Ma Yong, Yang Yang, Explanation on Value of Low-carbon Tourism and Reconstruction of Development Model, Ecological Economy,2015.03 